\title{
Fronteiras sociais e simbólicas no espaço público liminar: Um estudo de caso
}

Social and Symbolic Borders in the Liminal Public Space: A Case Study Frontières sociales et symboliques dans l'espace public liminaire: une étude de cas

\section{Wellington Maciel}

\section{OpenEdition}

\section{Journals}

\section{Edição electrónica}

URL: http://journals.openedition.org/rccs/6766

DOI: $10.4000 /$ rccs.6766

ISSN: 2182-7435

\section{Editora}

Centro de Estudos Sociais da Universidade de Coimbra

Edição impressa

Data de publição: 1 Dezembro 2017

Paginação: 47-68

ISSN: 0254-1106

\section{Refêrencia eletrónica}

Wellington Maciel, «Fronteiras sociais e simbólicas no espaço público liminar: Um estudo de caso », Revista Crítica de Ciências Sociais [Online], 114 | 2017, colocado online no dia 20 dezembro 2017, criado a 19 abril 2019. URL : http://journals.openedition.org/rccs/6766 ; DOI : 10.4000/rccs.6766 


\section{WELLINGTON MACIEL}

\section{Fronteiras sociais e simbólicas no espaço público liminar: Um estudo de caso*}

Este artigo discute a emergência do que se pode chamar espaço público liminar e a natureza das desigualdades que se estruturam segundo os condicionantes topográficos que Ihe dão substância. Busca-se apontar a especificidade das marcações e das fronteiras sociais e simbólicas, tomando a Praia do Futuro, em Fortaleza (Ceará, Brasil), como caso típico. Argumenta-se que a característica do espaço urbano e as práticas sociais que o individualizam no interior de uma cidade são fatores que não podem ser menosprezados na análise das novas formas de desigualdades no Brasil contemporâneo. A particularidade deste trabalho está em contribuir para o debate sobre a articulação entre o espaço urbano e as apropriações simbólicas associadas ao lazer praiano.

Palavras-chave: direito ao espaço público; fronteiras sociais e simbólicas; lazer; Praia do Futuro; praias.

\section{Introdução}

Os habitantes sempre imaginam habitar numa Aglaura que só cresce em função do nome Aglaura e não se dão conta da Aglaura que cresce sobre o solo. E mesmo para mim, que gostaria de conservar as duas cidades distintas na mente, não resta alternativa senão falar de uma delas, porque a lembrança da outra, na ausência de palavras para fixá-la, perdeu-se.

Ítalo CaLvino (1998: 34)

* As discussões travadas no presente artigo incorporam parte de minha tese de doutorado (ver Maciel, 2011). 
Se a opção por utilizar uma epígrafe tem por finalidade dar ênfase a um pensamento que, de certa forma, embasou a origem de um trabalho acadêmico, pode dizer-se que a epígrafe citada cumpriu esse objetivo. O caso de Aglaura, uma das cidades invisíveis imaginadas por Ítalo Calvino (1998), parece se aplicar à Praia do Futuro. ${ }^{1}$ Em ambas, a tensão entre "nome" e aquilo que "cresce sobre o solo" é a característica mais assinalada. Se, de um lado, Calvino situa a necessidade de se optar por um ou outro dos caminhos que levam a conhecer Aglaura, compreendo que, em relação à Praia do Futuro, deve-se procurá-la em ambos os registros. Somente assim, considerando-os simultaneamente, se pode adentrar nas suas dinâmicas sociais.

Embora a Praia do Futuro não seja considerada cidade como Aglaura, entender o modo como habitantes, mas também visitantes, empresários e poder público, se reportam a esse local situado na zona costeira de Fortaleza pode ser revelador de mudanças em curso nas maneiras de nomear a capital do estado do Ceará. Fortaleza possui um conjunto de traços que alimentam alguns dos "nomes" mais divulgados no país e no exterior, como os de "cidade das belas praias", "capital do sol", “das jangadas" e dos "verdes mares". É no seu litoral que se reúnem os referenciais com amparo nos quais os aspectos de "cidade praiana" são ressaltados e sedimentados em cartões postais ${ }^{2}$ e nas representações de moradores e turistas que se dirigem a ela.

Apesar da imagem mais divulgada de "cidade praiana", até um observador menos atento é capaz de apontar algumas diferenças no litoral, levando em conta para isso os usos e apropriações mais visíveis do seu lazer praiano. De acordo com esse critério, as praias de Fortaleza podem ser classificadas segundo sua localização, os públicos frequentadores, as estruturas, os equipamentos de lazer e a presença maior ou menor dos poderes público e privado.

Conforme esses parâmetros de comparação, o lazer da Praia do Futuro apresenta algumas peculiaridades que o individualizam em face das outras praias: está localizado ao leste; o trecho de praia onde está concentrado é composto por instalações privadas, conhecidas por barracas de praia (espécies

\footnotetext{
${ }_{1}^{1}$ A Praia do Futuro se encontra ao leste de Fortaleza, capital do estado do Ceará, Brasil. Divide-se, do ponto de vista da administração municipal, em duas grandes áreas: Praia do Futuro I, que tem início nas proximidades dos bairros Mucuripe e Cais do Porto, indo até à Rua Renato Braga, nas imediações do Clube dos Engenheiros; e Praia do Futuro II, que segue desse trecho até ao rio Cocó, na divisa com a Praia da Sabiaguaba, último trecho de orla da cidade.

2 Para uma análise das representações de lugares turísticos presentes em cartões postais, ver Barreira (2008: 107-128).
} 
de restaurantes, bares e casas de shows à beira-mar), responsáveis por atrair um elevado número de banhistas durante todo o ano; os públicos que frequentam suas barracas são os mais diversificados em termos de renda, profissão, idade, gênero, opções sexuais, escolaridade e origem.

As características singulares desse lazer, em grande parte identificado pelas barracas, transformam a então "praia mais badalada da cidade" num campo fértil para a investigação das divisões e desigualdades que ocasionam mudanças na classificação de Fortaleza como "cidade praiana". A ausência de um contrato público em torno dos interesses nesse lazer é outra característica marcante, alcançando grande visibilidade na imprensa local e nacional.

O presente artigo se propõe discutir a emergência do que se pode chamar espaço público liminar ${ }^{3}$ e a natureza das desigualdades que se estruturam segundo os condicionantes topográficos que lhe dão substância. Busca-se apontar ainda a especificidade das marcações simbólicas no contexto do espaço público liminar, tomando a Praia do Futuro como caso típico. Argumenta-se que a característica do espaço urbano e as práticas sociais que o individualizam no interior de uma cidade são fatores que não podem ser menosprezados ao se analisar as novas formas de desigualdades no Brasil contemporâneo.

Alguns autores (Bauman, 2003, 2009; Bourdieu, 2007; Canclini, 2008; Certeau, 2003; Douglas e Isherwood, 2009; Featersthone, 2007; Urry, 2001; Zukin, 2000) têm se dedicado a discutir as fronteiras sociais e simbólicas produzidas durante as práticas de lazer e consumo. A ênfase é dada à maneira como os conflitos se estruturam e ao modo como as divisões são contestadas no âmbito das mudanças que afetam Estado, economia e sociedade. A particularidade do presente artigo está em contribuir para esse debate a partir da articulação entre o espaço urbano e as apropriações simbólicas associadas ao lazer praiano.

O balanço do estado da arte dos estudos internacionais com interesse em desvendar as tramas contemporâneas do espaço público liminar e

\footnotetext{
3 Adoto aqui a noção de espaço liminar de Zukin (2000): "O espaço incita e imita a ambiguidade. Os sítios específicos da cidade moderna são transformados em espaços liminares pós-modernos, que tanto falseiam como fazem a mediação entre natureza e artefato, uso público e valor privado, mercado global e lugar específico. Liminaridade, aqui, remete ao conceito de Victor Turner, subvertido por Jean-Christophe, que alterou o significado antropológico original de 'transição de certos grupos' [...] conferindo ao termo um novo significado social e cultural de 'espaço transicional'. Nomear um espaço como 'liminar', contudo, não simplifica o fenômeno. Misturando funções e histórias, um espaço liminar situa o usuário a 'meio caminho' entre instituições” (ibidem: 82). Assim como Zukin, pretendo sugerir com a expressão espaço público liminar um modo de apreender, por um lado, a confluência perversa entre o público e o privado nas práticas do lazer contemporâneo e, por outro, a indeterminação identitária dos espaços urbanos pelos usos diferenciados do lazer na atualidade.
} 
as desigualdades criadas revela uma pluralidade de enfoques. Em todos eles a cidade é palco das novas reterritorializações sociais advindas da globalização (Fortuna e Santos Silva, 2005; Sassen, 1996). Smith (2006) afirma que vivenciamos uma gentrification generalizada, que alcança áreas das cidades até então marginalizadas, transformadas, agora, em bens econômicos para o consumo cultural. Harvey (2004) e Featherstone (2007) apontam para o modo como certas paisagens urbanas "pós-modernas" são inseridas hierarquicamente nas novas dinâmicas urbanas dos fluxos turísticos e o surgimento de novos estilos de vida segregados, tais como as insólitas "tribos urbanas" (Maffesoli, 2014). O consumo dessas áreas gentrificadas, segregadas, que erguem barreiras físicas para isolar e afastar sujeitos considerados perigosos, é o tema privilegiado das pesquisas de Canclini (2008) na Cidade do México. Em outro registro, Urry (2001) aponta para a "fuga do cotidiano" e Zukin (1991) e Davis (2009) identificam paisagens de poder nos atuais cenários urbanos das cidades globais em oposição às paisagens vernaculares. ${ }^{4}$

\section{Uma praia dividida pelos usos}

Um das vias possíveis de acesso às classificações produzidas sobre lugares praianos são os guias de viagens. Freire (2008), no seu "guia de praias", apresenta uma sugestiva imagem da Praia do Futuro: "a praia das megabarracas". No início da introdução, ele lança a seguinte pergunta: "Qual é a nossa praia?”. A resposta que oferece é significativa a propósito da maneira como essa zona é vista atualmente por visitantes mais seletivos e empresários: "Não temos as praias mais bonitas do mundo, mas temos as praias mais gostosas do mundo." Fiel a essa linha de argumentação e pondo como garantia sua experiência por vários lugares, Freire situa a Praia do Futuro em relação a um referente mais próximo - a Beira-Mar, em Fortaleza:

Água verdinha, um belo recorte, calçadão, prédios chiques, bons hotéis com vista para o mar - esqueça: tudo isto está a $5 \mathrm{~km}$ de distância na bonita porém poluída

\footnotetext{
${ }^{4}$ No Brasil, alguns estudos são pioneiros na análise dos usos do litoral por grandes empreendimentos privados e no modo como as relações sociais são modificadas. É o caso do clássico livro do antropólogo Thales de Azevedo (2016), que analisa o fenômeno da "cultura de praia" no Brasil. Influenciados por Azevedo, cito os importantes trabalhos de O'Donnell (2013), que trata da ocupação urbanística e dos usos da Praia de Copacabana quando de seu surgimento, e Linhares (2013), a propósito de Fortaleza. Para uma análise comparativa dos usos praianos sugiro a leitura do texto de Goldemberg (2007). É importante frisar que os estudos no Brasil buscam estabelecer diálogos com a bibliografia internacional, incorporando, criticamente, conceitos tais como paisagens de poder, espaços gentrificados, espaço urbano pós-moderno e a ideia de liminaridade.
} 
orla da Beira-Mar, imprópria para o banho. Sem outra alternativa, Fortaleza fez da Praia do Futuro sua praia urbana. Extensa, reta, de faixa larguíssima de areia, vento constante e ondas intermitentes, não seria a praia mais agradável do mundo. Mas daí o fortalezense inventou as megabarracas de praia - verdadeiros clubes à beira-mar, que compensam a falta de conforto natural da praia com uma estrutura inacreditável.5 (2008: 42)

Conforme lembra Woodward (2007), é por meio do significado produzido pelas representações das divisões que os atores dão sentido às suas experiências cotidianas. Segundo esse viés, não se vai à Praia do Futuro sem informações detalhadas acerca das localizações e qualidades das barracas. Com isso não quero acentuar que, mesmo entre as barracas mais procuradas não haja diferenças importantes: há instalações grandes e médias. A divisão entre "praia velha" e "praia nova" incorpora, pois, uma variante simbólica que reforça e alimenta suas experiências atuais. ${ }^{6}$ Essas divisões foram tecidas concomitantemente ao surgimento e crescimento das barracas-complexos após o Projeto Esta Praia Tem Futuro de 1999. Segundo essa perspectiva, as divisões "praia velha" e "praia nova” constituem as formas típicas de seu ordenamento socioespacial nos últimos anos.

Essas classificações possibilitam, no primeiro momento, inferir que elas não designam apenas momentos distintos na ocupação da faixa de praia, como poderia parecer à primeira vista, mas parecem revelar elementos

\footnotetext{
${ }^{5}$ No mesmo texto é possível encontrar descrições e avaliações feitas por Freire (2008) das "megabarracas" e de suas temporalidades socioespaciais num capítulo dedicado à Praia do Futuro: "Das megabarracas da Praia do Futuro, a CrocoBeach é a mais incrementada, com um deck sob o coqueiral; a Atlântida, a mais bem decorada; a Vila Galé, a mais calminha; a Vira Verão, o point da geração saúde, a única que mantém as cadeirinhas de madeira e as cabaninhas de palha de antigamente. Porém é a Cabumba, a preferida dos alternativos e do pessoal LGBT. Quinta-feira acontece um fenômeno: meia cidade vai à praia à noite para comer caranguejo." Freire (ibidem: 9) encerra a introdução do seu "guia" lembrando que: "Nossas praias são gostosas quando desertas e também muvucadas. São gostosas com ondonas ou com piscininhas. Com falésias, com dunas ou com coqueiros. São gostosas com prédios, também. Este guia foi feito para ajudar a você a aproveitar as mais gostosas praias do Brasil".

${ }^{6}$ Sobre o lugar conferido a essas marcações simbólicas pelas matérias jornalísticas, cf. o Jornal O Povo, de 28 de agosto de 2005, "Praia do Futuro. Entre o cuidado e o desprezo". Woodward (2007: 14-15) oferece vias para análise das divisões desse tipo ao tratar das "identidades". Segundo a autora, "a identidade é relacional e a diferença é estabelecida por uma marcação simbólica relativamente a outras identidades; a identidade está vinculada também a condições sociais e materiais; o social e o simbólico referem-se a dois processos diferentes, mas cada um deles é necessário para a construção e a manutenção das identidades; as identidades não são unificadas". Por último, Woodward levanta o seguinte questionamento que serve para pensar o lugar de poder ocupado pelos que integram a Associação dos Empresários da Praia do Futuro$\mathrm{AEPF}$ no interior do espaço social em análise: "Por que as pessoas investem nas posições que os discursos da identidade lhe oferecem?".
} 
de ordem simbólica importantes que interferem nos atuais processos de classificação e redefinição de sua qualidade de praia, conforme as divisões materiais e simbólicas, como revela a fala da Presidente da AEPF:

Tudo que a Associação tem feito é melhorar a Praia do Futuro como destino turístico e isso tem sido feito pelos barraqueiros e com certeza existe um papel da AEPF nessa evolução. Com o Projeto Esta Praia Tem Futuro o que foi que a Associação fez? Nós dividimos a Praia em cinco setores e aí fica mais fácil conversar com os barraqueiros. Pega ali o setor da [barraca] da 'Tia'... senta e conversa. Vê as necessidades: problema de iluminação problema de lixo, problema com animais soltos. Sempre nessa ordem. O primeiro trecho, que a gente chama de 'Trecho 1', é o que começa no [bairro] Serviluz e termina aqui na Rua Renato Braga, onde poderia citar a barraca da 'Tia', o 'Dionízio', o 'Dallas'. São barracas já de muito tempo. Aí vem esse trecho que nós chamamos de 'Trecho das barracas padronizadas', porque elas têm de certa forma o mesmo padrão arquitetônico, que são essas pirâmides, o tipo de vegetação. Nesse setor, você tem a 'Marulhos', a 'CrocoBeach', a 'Vira Verão', o 'Cuca Legal', que são quatro barracas mais destacadas, eu diria assim. $\mathrm{Na}$ minha opinião, essas barracas têm um ponto fortíssimo que é a arborização, certo? E uma coisa que a gente chama de ambientação, que é essa coisa rústica, essa coisa de primar por essa ornamentação, por essa coisa de carnaúba, de palha, de acessórios que dão embelezamento sem sair muito do rústico, sabe? Eu acho que isso agrada muito às pessoas. Eu acho que essa valorização do rústico é uma coisa da nossa própria cultura, sabe? De querer enaltecer o que é nosso, de valorizar o que é nosso. Isso traz um diferencial bem grande pra esse setor. Bem, aí depois nós temos o 'Setor 3', onde está a 'Cabumba', onde está o 'Biruta', a 'América do Sol'. Tem o mesmo estilo de construção e de público. Depois, nós temos o 'Quarto Setor' que é o da [Praça] 31 de Março, onde estão aquelas barracas que hoje dão apoio muito grande aos romeiros que vêm do [município de] Canindé, aos caminhoneiros. É um pólo que atrai esse tipo de freqüentador. Esse é o 'Setor quatro'. Depois nós temos o 'Setor 5' que inclui todas as barracas que estão da Avenida Santos Dumont pra lá [na direção da Praia do Caça e Pesca], que também tem um certo padrão arquitetônico bem parecido com as barracas do 'Trecho 2'. Mas sem dúvida nenhuma os 'trechos' mais sacrificados hoje em termos de freqüência é o da Praia do Futuro 'velha', que é o 'trecho 1, e o ‘trecho da 31 de Março'. São barracas que não atendem muito o gosto dos freqüentadores. Estão mais abandonadas. ${ }^{7}$

\footnotetext{
${ }^{7}$ Entrevista concedida pela presidente da Associação dos Empresários da Praia do Futuro e proprietária da barraca Marulhos, em 10 de janeiro de 2011. Além de presidente da AEPF, a Senhora Fátima é ainda diretora da Associação Brasileira de Bares e Restaurantes (ABRASEL), diretora do Sindicato de Bares, Restaurantes, Buffets, Barracas de Praia e Similares (SINDREST), secretária do Fórum do Turismo-CE e membro do Grupo Gestor de Qualidade em Serviços, ligado ao Serviço de Apoio à Micro e Pequena Empresa (SEBRAE).
} 
$\mathrm{Na}$ "praia nova", que tem início no trecho entre a Praça 31 de Março e a Rua Renato Braga, estão os complexos turísticos maiores e mais caros representados pelas barracas-complexos temáticas e mais sofisticadas (Chico do Caranguejo, Itapariká, CrocoBeach, Marulhos, Vira Verão, Vila Galé, CocoBeach, América do Sol), compostas por espaços restritos a certos frequentadores dispostos a consumir os serviços mais diferenciados neles oferecidos.

Para compreender o reforço dessa diferença em relação à "praia velha" e a maneira como esta é vivida na "praia nova", é preciso atentar para a forma como as relações sociais são ordenadas. Essas classificações simbólicas servem, nesse sentido, ao propósito não necessariamente consciente de produção e reprodução dos grupos por meio de atividades que conferem sentido às suas práticas sociais com base nas quais o outro (vendedores ambulantes, a "praia velha" e seus proprietários) é incluído ou excluído dos processos de identificação.

Esses elementos simbólicos atuam hoje como componentes fundamentais para imprimir-lhes as características que parecem tão eficazes no que diz respeito à orientação cotidiana daqueles que se dirigem à "praia nova": policiamento militar, segurança privada nas barracas, mecanismos de vigilância e práticas panópticas (Foucault, 2004), como câmeras espalhadas pelo trecho onde se encontram os grandes empreendimentos e torres do Projeto Guardiões da Praia, implantado em 2006, além de limpeza urbana periódica, fiscalização de trânsito, iluminação pública, coleta de lixo, vias de acesso calcetadas, salões para apresentações artísticas e estrutura de lazer e turismo diferenciada.

$\mathrm{Na}$ "praia nova", o tempo dispendido nas barracas não apenas se distancia de qualquer interpretação que o possa associar ao desperdício do mesmo, como também revela a importância desses espaços como lugares de marcação e pertencimento. Os obstáculos físicos (cercas, muros, tapumes e grades) utilizados pelas barracas são alvo de constantes conflitos entre empresários e o Patrimônio da União, por se tratarem de obras de ampliação das estruturas e implicarem a proibição do acesso de outros frequentadores aos ambientes restritos das barracas-complexos.

É durante as ocasiões em que ocorrem shows e eventos e nos dias onde o trecho de praia recebe um público maior, como o "domingo na praia" e a "quinta do caranguejo", que as fronteiras simbólicas mais se deslocam, o que redefine o sentido jurídico de praia e contribui para o acirramento dos conflitos em torno dos seus usos. Nesses dias, se intensificam os conflitos envolvendo empresários, Patrimônio da União e vendedores ambulantes, com base nos quais as fronteiras em relação ao exterior das barracas são reforçadas. 
A maneira como essa diferença é exercitada passa pela forma como esse exterior é representado. Em contraposição ao espaço ocupado pelas barracas, as areias $^{8}$ são tomadas como principal lugar dessa marcação da diferença. As qualidades mais ressaltadas dessa área são insegurança, desorganização e violência, por conta dos constantes assaltos a banhistas. A presença ou ausência de cofres presos às palhoças das barracas é um fator determinante para a permanência em uma delas. É comum os frequentadores, ao optar por tomar banho de mar, se sentirem obrigados a deixar seus pertences nesse dispositivo. Essa medida de segurança por parte de alguns empresários é exaltada como um dos diferenciais da "praia nova".

É no "domingo na praia" que acontecem mais roubos e assaltos nas areias. Essa área pode ser descrita como um espaço público liminar, no sentido de Zukin (2000), uma fronteira tênue entre espaços de sociabilidade distintos que as barracas representam, onde se encontram os habituées, e os usos mais diversificados da faixa de praia. Nelas, andar desatento ou sem conhecer suas lógicas pode significar deparar-se com atores e práticas considerados marginais. São recorrentes nas altas estações roubos de cordões, pulseiras, relógios e máquinas fotográficas de pessoas mais desavisadas, sobretudo turistas.

A presença seletiva de serviços considerados públicos concorre, assim, para a produção de quadros diferenciados. É o caso do Projeto Guardiões da Praia de 2006, uma iniciativa da Secretaria de Segurança Pública do Estado do Ceará, para combater casos de violência e assaltos nesse trecho do litoral de Fortaleza. Os aspectos considerados de insegurança e violência (ver Bauman, 2003; Caldeira, 2003, acerca da proliferação dos enclaves fortificados na sociedade contemporânea) foram os principais motivos levantados por empresários e pelo Poder Público para a implantação do Projeto, considerado uma intervenção relacionada ao Projeto Esta Praia Tem Futuro.

A distribuição das instalações deveria atender aos trechos onde os conflitos fossem mais graves. O Projeto consistiu na construção de torres de observação distribuídas ao longo da faixa de praia. Cada uma delas está localizada em pontos estratégicos da "praia nova", sob a alegação de se constituírem pontos principais de insegurança no mar e nas areias. Embora sua implantação original tivesse por finalidade cobrir toda a orla, o Projeto passou a contar, apenas, com a presença de policiais e salva-vidas nas torres onde se encontram os maiores complexos de lazer.

\footnotetext{
${ }^{8}$ Além das areias, os acessos e as dunas altas e dunas baixas constituem as divisões topográficas mais visíveis da Praia do Futuro.
} 
Ao todo foram instaladas nove torres de observação, tendo como referência algumas barracas consideradas mais frequentadas - Arpão, Itapariká, Chico do Caranguejo, Vila Galé, América do Sol, Croco Beach, Coco Beach e Barraca da Tia. À exceção desta, todas são consideradas por moradores, empresários, turistas e Poder Público como representantes da "praia nova".

$\mathrm{Na}$ "praia velha", em contraste, as representações mais comuns reservam a esse trecho qualidades negativas e desviantes, lugar da marginalidade, do consumo de drogas, da ausência de infraestrutura e da prostituição. Foi na barraca Vela Latina, onde ocorreu, em 2001, a morte de seis portugueses que estariam nesse lugar em busca de turismo sexual. O fato obteve repercussão internacional, o que colaborou ainda mais para a produção de imagens negativas sobre o local.

Na matéria "Esquecida pelo poder público", o jornal Diário do Nordeste, de 20 de julho de 2010, revela dimensões importantes das novas divisões simbólicas. $\mathrm{Na}$ "praia velha",

[...] o cenário é desolador. As estruturas das barracas parecem esqueletos sobre a areia. Muitas estão em ruínas, sem teto, com os escombros servindo de abrigo a famílias sem-teto ou mesmo usuários de drogas. A areia tomou conta do pouco que permanece de pé, sendo acumulada entre as barracas e chegando a soterrar algumas estruturas. No lugar dos desejados clientes, só se veem cães, gatos e jumentos por todos os lados.

Com aproximadamente dois quilômetros de extensão, a "praia velha" conta com 36 das mais de 150 barracas existentes nas areias, denominadas aqui de barracas-artesanais, sendo, paradoxalmente, o único trecho que possui todas as barracas regularmente cadastradas no Patrimônio da União. Dessas, apenas 12 estão atualmente em funcionamento, como a barraca "Zé da Praia". Do ponto de vista do seu proprietário, há certa convergência na associação comumente feita entre decadência da "praia velha" e a presença de frequentadores desviantes.

Em 1976, não tinha nada aqui não, cara. Era só areia. Isso aqui só ia até o Casarão. Pra lá, no Caça e Pesca, fizeram uma pista de piçarra. Não tinha nada aqui não. Aqui só prestou na época do César Cals Neto. Essa Praça aí [a 31 de Março] quem fez foi ele, ali onde ta a CrocoBeach. De lá pra cá não foi feito mais nada. Aqui tinha o 'Meu Garoto', 'Cheiro do Mar'... As barracas aqui era tudo de lona. Eu cheguei aqui em 1972. Aqui tinha o 'Maria Maria', tinha a 'Maré Manso', 'Dona Joaninha', tinha 'O Bené', o 'Havaî', tinha o 'Atlântida', o 'Aconchego do Mar'. 
O pessoal que vinha era de Fortaleza mesmo, era lotação. Eu vendia muita caixa de cerveja. Aqui tinha muito advogado, engenheiro. O que acabou com nós aqui foi a insegurança. Acabou com nós. Naquela época a gente tinha freguesia, dinheiro. Aqui tá abandonado. ${ }^{9}$

A "praia velha" é reiteradamente lembrada por empresários da "praia nova" como antítese do que se entende por praia, num rico processo de classificação simbólica. Essa marcação de lugares (Woodward, 2007; Leite, 2001), por sua vez, se alimenta de uma temporalidade socioespacial. É marcante o lugar ocupado pelo consumo de caranguejos e outros alimentos durante os dias em que a Praia do Futuro é redefinida. Essa relação se intensifica durante os momentos em que ela recebe um público maior e mais diversificado.

A visibilidade alcançada dentro e fora da cidade como "a praia da cidade" ou "a praia mais badalada" se tornou a imagem da Praia do Futuro mais conhecida para moradores, visitantes, empresários e atores públicos. É em decorrência, em grande parte, dessas imagens mais positivas que o trecho de praia é citado nos últimos anos em revistas nacionais e internacionais como único do tipo no Brasil a possuir grandes complexos de lazer para suporte das necessidades dos banhistas que a eles se dirigem.

Embora a Praia do Futuro tenha recebido diversas intervenções com vista a mudar seus usos, principalmente com início nos anos 1980, década em que se intensificou a procura de práticas de lazer e proliferaram propostas de planejamento, foi só na década de 1990 que uma intervenção mais complexa foi planejada. Essa reviravolta teve início em 1999, quando a AEPF e a Secretaria de Turismo do Estado-SETUR lançaram o Projeto Turístico Esta Praia Tem Futuro, um convênio por meio do qual um conjunto de problemas deveria ser solucionado, tais como infraestrutura, imagem e estruturas das barracas, com a finalidade de construir, no "presente", uma "praia de futuro". ${ }^{10}$

Consoante o Projeto, ficaria sob responsabilidade da SETUR uma ampla avaliação do potencial econômico da Praia, com vista a torná-la ponto de atração dos fluxos de lazer e turismo dirigidos a Fortaleza

\footnotetext{
${ }^{9}$ Entrevista concedida por "Zé da Praia”, proprietário da barraca de mesmo nome, em 05.08.2011. ${ }^{10}$ Como dito na abertura deste artigo, tendo por base Ítalo Calvino, a tensão entre "nome" e o que "cresce sobre o solo" é a característica mais comum à Praia do Futuro. Depois de o lugar ter despontado como "futuro urbano" na década de 1950, outras classificações foram sendo construídas à medida que a Praia ia crescendo: "praia do presente", na década de 1970, em referência à constatação das primeiras construções a "brotar na areia fina" e "praia do caos urbano", na década de 1980, imagem associada ao modo desordenado de ocupação do lugar.
} 
com base em ações estratégicas de marketing, além de intervenções em segurança e limpeza urbana. À AEPF caberia a ampliação e modernização das barracas para incrementar novos frequentadores e outras possibilidades de negócio.

As centenas de vendedores ambulantes que ocupam boa parte da orla nos finais de semana são alvo de constantes conflitos, pois estariam violando áreas a eles interditas pelos empresários. Proibidos de permanecer nos setores restritos das barracas de praia, com a justificativa de que estão perturbando o lazer dos frequentadores e roubando banhistas, os vendedores ambulantes, ao criar suas "táticas" (Certeau, 2003) de sobrevivência, parecem revelar dimensões políticas importantes presentes em suas práticas sociais.

\section{A praia como espaço público liminar}

No final da década de 1990, a Praia do Futuro passou por intensa mudança nos usos e imagens associadas ao "caos urbano" que a teriam caracterizado na década de 1980. Alguns barraqueiros associados à AEPF modificaram as estruturas de suas barracas, levando-as a crescer e a avançar nas areias. Isso resultou em conflitos judiciais com o Patrimônio da União, órgão encarregado pelo gerenciamento dos chamados "bens públicos" federais. Esses conflitos passaram a gravitar em torno da acusação de privatização desses bens por parte das barracas e das contradições de usos que elas foram imprimindo ao lazer.

Segundo a matéria do jornal O Povo de abril de 2010, "O litoral que Fortaleza não enxerga", a cidade teve parte dos 34 quilômetros de praia reduzida ao longo das duas últimas décadas. $65 \%$ dela sofre de "uso inadequado", como poluição, insegurança ou ocupação irregular e apenas 12 quilômetros, o que compreende os trechos de praia da Beira Mar e Praia do Futuro, "estão acessíveis à maioria da população", sendo estas as "duas áreas para lazer e turismo" do fortalezense.

A mesma matéria do jornal O Povo informa ainda as praias que estavam sendo deslocadas: da Barra do Ceará ao Kartódromo, "a praia é o quintal de uma urbanização caótica"; da praia Leste-Oeste "não se enxerga o mar. $\mathrm{O}$ acesso é restrito aos moradores da área. A falta de segurança e a poluição da água afastam outros visitantes"; na Praia de Iracema, "a praia praticamente não existe”. Só a partir do trecho entre as ruas Idelfonso Albano e Rui Barbosa "a praia volta a aparecer".

Ao longo da Beira Mar, a areia some e reaparece [...] São tantas construções ao longo do calçadão e da praia que em muitos pontos não é possível contemplar o 
mar [... $\mathrm{Na}$ curva da orla, entre a Beira Mar e a Praia do Futuro, nos primeiros quilômetros do chamado setor leste, o porto, o Serviluz e os tanques de combustível da Petrobrás bloqueiam a praia. Será que damos a atenção devida às nossas praias?

Diferentemente da Praia de Iracema, caracterizada, entre outras coisas, pelo elevado valor do chamado solo urbano, o que se reflete na quase ausência de terrenos para novas construções, a Praia do Futuro sofre de algo bem distinto. A ocupação intermitente de prédios residenciais e comerciais tem sua contraposição no crescimento das construções de lazer e turismo. A construção de hotéis e pousadas de luxo aumentou nos últimos anos, para além da das barracas de praia. Foram estas, no entanto, as armações que mais cresceram e avançaram em direção ao mar. Esse avanço fez a União exercer um controle mais intenso nos últimos anos, proibindo novas construções e embargando obras em andamento. O objetivo foi reduzir os movimentos desses empreendimentos no interior das dinâmicas de lazer. As medidas adotadas visavam reestabelecer parâmetros técnicos para esse tipo de construção.

A Ação Civil Pública do Ministério Público Federal de 2005 foi deflagrada com esse objetivo. Ela exige a retirada de todas as armações arquitetônicas utilizadas como parte das estruturas das barracas, alegando que se expandiram transpondo os limites previstos nas legislações de gerenciamento costeiro que incidem sobre as áreas de praia do Brasil. Por conta disso, os dispositivos físicos utilizados pelas barracas, por constituírem obras de ampliação das estruturas de praia, proibiam o acesso de outros frequentadores da faixa de praia aos ambientes restritos dos novos espaços de lazer.

Em razão do avanço de construções turísticas e de lazer em áreas consideradas públicas pertencentes à União, várias medidas administrativas e jurídicas foram adotadas em âmbito federal, estadual e municipal, com o intuito de estabelecer parâmetros técnicos para organizar os usos dos chamados "bens públicos de uso comum do povo". A principal dessas legislações, a Lei Federal de Gerenciamento Costeiro (Lei 7.661, artigo 10, de 16.05.1988), considera a praia um

bem público de uso comum do povo, sendo assegurado, sempre, livre e franco acesso a elas e ao mar, em qualquer direção e sentido, ressalvados os trechos considerados de interesse e segurança nacional e incluídos em áreas protegidas por legislação específica [...] entende-se por praia a área coberta e descoberta periodicamente pelas águas acrescida da faixa subsequente de material detrítico, 
tal como areias, cascalhos, seixos e pedregulhos até o limite onde se inicia a vegetação natural, ou, em sua ausência, onde comece um outro ecossistema.

No âmbito do Estado do Ceará, a Lei 13.796, de 30.06.2006, institui a Política Estadual do Gerenciamento Costeiro e o Plano Estadual de Gerenciamento Costeiro. Nesta lei aplicam-se as mesmas definições jurídicas de 1988 à praia. Do ponto de vista municipal, a Lei 7.987 de 1996, a Lei de Uso e ocupação do Solo, nos seus artigos 109, 111 e 112 estabelece que a faixa de praia "parte da orla marítima do município de Fortaleza, constitui-se da área coberta e descoberta pelas águas marítimas". Seu parágrafo único prevê ainda que "todas essas faixas são "non aedificandi' e se destinam ao lazer e à prática de atividades esportivas".

Por outro lado, a primeira legislação a reconhecer o chamado domínio patrimonial desses bens no Brasil data de 1946 (Decreto-Lei 9.760). Nela são lançadas as bases conceituais ${ }^{11}$ que fundamentaram as legislações posteriores: o Decreto-Lei 2.398, de 1987, que trata da emissão de foros e taxas de ocupação relativos aos imóveis da União; a própria Constituição de 1988, que no seu artigo 20 especifica quais são os bens pertencentes à União; a Lei 9.636, de 1998, que dispõe sobre sua regularização e administração, alterando aspectos das leis citadas há pouco; o Projeto de Lei, de autoria do ex-senador Paulo Hartung, que propõe a alteração conceitual dos "terrenos de marinha" presente na lei de 1946; o Decreto 3.725 , de 2001, que muda alguns aspectos relativos à administração desses bens patrimoniais previstos pela lei de 1998; e, mais recentemente, o Projeto Orla (MMA/ MPOG - Brasil, 2002: 18).

Neste projeto federal, é proposto o reordenamento urbanístico da orla marítima das principais cidades brasileiras. É dito que

a garantia de acesso às praias, como bem público, e, consequentemente, a manutenção da função social dessa faixa altamente valorizada do território nacional, necessita ser enriquecida pela responsabilidade municipal na gestão, ampliando as possibilidades de solução de conflitos de uso e a reversão dos processos de degradação.

A versão municipal do projeto em Fortaleza, o Projeto Orla Fortaleza, de 2006, parcialmente implementado, tem como meta traçar ações para

\footnotetext{
${ }^{11}$ Refiro-me aqui aos chamados "terrenos de marinha" e os "terrenos acrescidos de marinha", ambos, por sua vez, dependentes da definição presumível da chamada Linha de Preamar-Média, de 1831, para serem demarcados. A expressão "de marinha" faz referência aos bens relacionados à influência ou proximidade com o mar.
} 
sua orla na busca de resolver os conflitos específicos de um total de cinco trechos de praia da cidade. No caso da Praia do Futuro, está prevista a retirada de todas as barracas, já que o Projeto passou a compor a Ação Civil Pública de 2005. Essa determinação resulta em constantes lutas judiciais entre empresários e o Patrimônio da União em torno das redefinições semânticas do sentido jurídico atribuído ao termo praia.

A respeito dessas lutas semânticas Depaule e Topalov (2001: 20) e Bourdieu (2008) reconhecem que a língua designa objetos, conferindo-lhes sentido. As classificações oficiais participam desse trabalho de sedimentar significados como estratégia de reprodução da ordem social. Essas mesmas classificações, contudo, obedecem a múltiplas variações da própria língua, segundo as diferentes posições que aí se inscrevem. Dessa forma, para os autores, elas convivem sempre com a possibilidade das discordâncias quanto ao acordo sobre o registro simbólico da ordem social. Essa observação parece se aplicar às recentes tentativas de modificação do sentido normativo dos chamados bens públicos.

Em 06 de agosto de 2013, ano de encerramento da Ação de 2005, a desembargadora federal do TRF da 5. ${ }^{a}$ Zona em Recife, Senhora Margarida Cantarelli, decidiu pela permanência definitiva das barracas de praia, exemplificando, no âmbito do Estado, a incorporação de sentidos particulares de praia pelos agentes públicos. Segundo a opinião de Cantarerlli, relatada pelo jornal O Povo, ${ }^{12}$

as barracas não foram construídas na área de praia, mas na chamada berma (pós-praia). Para chegar a essa conclusão, a desembargadora baseou-se na Lei Estadual de Gerenciamento Costeiro (lei 13.796/2006) e em perícia realizada pela Universidade Federal do Ceará (UFC), com o acompanhamento de engenheiros da Gerência Regional do Patrimônio da União (GRPU).

Conforme noticia ainda o mesmo jornal,

a magistrada também argumentou que os bens do Estado podem ser flexibilizados em virtude da finalidade para as quais se prestam. Assim, a desembargadora avaliou que a região da Praia do Futuro apresenta uma grande vocação turística e, também, levou em conta os empregos gerados pelas barracas e a importância dos serviços prestados por elas aos turistas e fortalezenses. No entanto, a decisão

${ }_{12}$ O Povo, de 07 de agosto de 2013, "TRF decide que barracas permanecem na Praia do Futuro". Em abril de 2017, a justiça federal decidiu novamente pela retirada das barracas de praia, cabendo ainda recurso. 
judicial determina a retirada de obstáculos de acesso à praia (como cercas e bambus), para que existam corredores livres para a circulação de pessoas. O documento também autoriza a demolição das barracas abandonadas, evitando que se tornem locais geradores de poluição ou favoráveis a prática de crimes.

Por conta das mudanças patrimoniais e conceituais, algumas medidas passaram a ser propostas nos últimos anos com a finalidade de flexibilizar a definição dos bens públicos federais. O Projeto de Lei de 1999 é importante nesse sentido, porque reconhece atualmente que as transformações patrimoniais fundamentais no âmbito do Estado deveriam se refletir em mudanças nas maneiras de nomear esses bens. Ainda que considere a titularidade da posse daqueles tipos de terrenos por parte da União, o Projeto de 1999 lembra que a não alteração de alguns parâmetros na legislação que os rege, como a presumível definição da Linha de Preamar Média de 1881, reconhecida pela lei de 1946, pode fazer da União a maior proprietária de áreas urbanas em muitos estados brasileiros o que resultaria num

contrassenso, pois é notório que, há já vários anos, vem sendo promovida substancial reforma patrimonial do Estado, objetivando deixar ao poder público apenas o cumprimento de suas funções básicas e essenciais [...] Como medidas iniciais, estamos propondo que seja reduzida de 33 (trinta e três) para 13 (treze) metros a área que deve constituir os chamados terrenos de marinha, a ser delimitada, porém, a partir do preamar-médio do ano de 1999. Isso, a nosso ver, particularmente em razão do encurtamento da área desse tipo de bem da União, contribuirá [...] para reduzir a atual margem de insegurança jurídica de que se ressentem muitos milhares de famílias.

Essa mudança jurídica e conceitual, que se reflete, segundo o Projeto, no "encurtamento da área desse tipo de bem", perpassa a grande maioria dos estados brasileiros. No que tange ao estado do Ceará, a Secretaria do Patrimônio da União (SPU) constatou imprecisões na demarcação daqueles terrenos, em particular na Praia do Futuro. Do total dos 560 quilômetros da costa cearense há uma margem de $10 \%$ de erro nas medições por falta de clareza dos "parâmetros demarcatórios". ${ }^{13}$

Importa dizer que as tentativas recentes de definir esses bens no Ceará levaram em conta estudos técnicos realizados em 1996 pela SPU,

${ }_{13}$ Esses dados foram coletados nas matérias do O Povo, de 26.03.2008: "Estudo técnico constata erros demarcatórios no litoral" e "Pontos do litoral com distorções". 
constatando-se no Estado "a superposição da faixa de terrenos de marinha com a praia e até com o mar”. Ela atinge várias praias do Estado, como, por exemplo, Prainha, no Município de Aquiraz, Taíba, em São Gonçalo do Amarante, as praias da Caponga e Batoque, boa parte das praias do Município de Caucaia e a praia de Mundaú, em Trairi.

Essa superposição foi acelerada pela intensificação dos usos para lazer e turismo no litoral, que passaram a ser incentivados no estado do Ceará nos anos 1990 (Gondim, 2007). Nessa década, Fortaleza foi inserida nos processos sociais nacionais e internacionais relacionados ao lazer e turismo através de grandes mudanças urbanas. Vale lembrar a esse respeito a construção do Aeroporto Internacional de Fortaleza (Maciel, 2010), a reforma da Ponte dos Ingleses, na Praia de Iracema, e o Centro Cultural Dragão do Mar (Gondim, 2007). Esses espaços urbanos passaram a ficar em sintonia com modelos e tendências mundiais, onde usos, estilos e funções se fundem ou se misturam.

A criação de centralidades urbanas passou a ser a principal estratégia adotada por muitas das gestões urbanas pelo mundo fora como parte de uma divulgada bem-sucedida estratégia de mudança urbana. Esse processo mais geral de especialização urbana que acompanha as transformações econômicas desde 1970 é apontado como saída para muitas cidades (Harvey, 2004). As mudanças arquitetônicas mais recentes pelas quais as barracas passaram podem ser tomadas em parte como uma tentativa de incorporar esses processos e como resposta dada pela Associação dos Empresários da Praia do Futuro (AEPF) às possibilidades econômicas abertas com a inserção de Fortaleza no mercado turístico.

\section{Considerações finais}

Tendo o presente artigo abordado a emergência do espaço público liminar e as marcações simbólicas que se estruturam no seu interior, argumenta que as novas formas de desigualdade no Brasil assumem uma versão particular no modo como a natureza do espaço urbano se articula com as práticas sociais que lhe dão substância. No que diz respeito à dinâmica interna do lazer da Praia do Futuro, os proprietários que, ao longo dos anos, estabeleceram parcerias em torno de propostas de planejamento público dos seus usos ou realizaram por conta própria modificações nas barracas, ocuparam posições de poder na direção dos planejamentos dos usos seguintes, dando origem às barracas-complexos.

Como se observou, na "praia velha" estão as barracas-artesanais, caracterizadas pela utilização de materiais menos sofisticados e por menor ou nenhum investimento material e simbólico. Seus proprietários são ainda 
conhecidos como barraqueiros e seu funcionamento não exige processos racionais de planejamento associados àqueles das empresas. É também a esse trecho que as imagens mais negativas de falta de segurança, limpeza pública e serviços de lazer de qualidade mais estão associadas.

$\mathrm{Na}$ "praia nova", em contraposição, identificada pelos empresários da AEPF, os "intermediários culturais" do lazer praiano (Bourdieu, 2007), como a "praia do presente", encontram-se os equipamentos que denominei de barracas-complexos, espaços que se assemelham ao que Featherstone (2007) e Zukin (2000) denominaram de espaços urbanos pós-modernos. Misturando funções e empresariamento das suas operações, essas barracas se tornaram os bens de consumo mais procurados e, visualmente, os mais utilizados do lazer praiano. Eles são responsáveis também pela movimentação de uma grande quantidade de produtos e serviços nas suas dependências.

Esse aspecto de liminaridade é visível nos tipos de decoração ou em espaços internos das barracas-complexos que fazem referência a estilos e citações culturais de outros tempos e lugares, como: jarros da Indonésia, pórticos romanos, castelos medievais, jangadas, varandas, lagos, entre outros artefatos. Em parte, essa citação decorre do encurtamento das distâncias e aumento dos contatos culturais intensificados pelo que Giddens (1991) denominou de desencaixes. Há, por conta disso, maior sensação de simultaneidade das ações e processos sociais entre os lugares assim distanciados. Ocorre, ainda, maior padronização dos formatos de espaços urbanos, já que gostos e estilos de vida passam a estar cada vez mais associados ao consumo dos mesmos "bens posicionais" (Douglas e Isherwood, 2009), o que tem resultado em mudanças no planejamento urbano das cidades em todo o mundo a fim de se aproximar desse formato multifuncional.

Um jeito talentoso de formular o problema abordado neste artigo, o da relação entre "nome" e o "que cresce sobre o solo", foi sugerido por Ítalo Calvino ao tratar da Aglaura, uma das suas cidades imaginárias. Para os moradores de Aglaura, a cidade parecia crescer apenas em função do nome. Ao se observar apenas a Aglaura que crescia sobre o solo, Calvino se limitou a deslocar o problema.

O exemplo da Praia do Futuro é representativo por envolver um problema semelhante, mas uma solução distinta, pelo menos para aqueles que hoje a classificam como principal lugar do lazer praiano no Brasil. A Praia do Futuro ensina que a melhor forma de compreender os significados de um espaço urbano no interior de uma cidade é atentar para as maneiras como "o que cresce sobre o solo" e "nome" são mobilizados segundo as 
posições ocupadas no seu interior. Foi em relação a esse modo de tratar do problema assinalado que empreendi importantes descobertas sobre a Praia do Futuro.

No presente texto houve o cuidado de assinalar as mudanças de usos, físicas, conceituais e patrimoniais que atingem esses "bens" no Brasil e, em particular, os conflitos quanto à sua redefinição. A Praia se revelou num caso típico das transformações que os usos voltados para lazer e turismo fazem da orla das principais cidades brasileiras e, por que não, do mundo. Fortaleza, conhecida internacionalmente como "cidade praiana", pode agora ser vista com outros olhares, a partir da Praia do Futuro. Resta saber de qual praia - a "do presente" ou a "do futuro".

\section{Referências bibliográficas}

Azevedo, Thales de (2016), A praia: espaço de sociabilidade. Salvador: EDUFBA.

Barreira, Irlys (2008), "Narrativas do olhar: Fortaleza em cartões postais", in Rogério Proença Leite (org.), Cultura e vida urbana: ensaios sobre a cidade. São Cristóvão: Editora UFS, 107-128.

Bauman, Zygmun (2003), Comunidade: a busca por segurança no mundo atual. Rio de Janeiro: Jorge Zahar.

Bauman, Zygmun (2009), Confiança e medo na cidade. Rio de Janeiro: Ed. Zahar.

Bourdieu, Pierre (2007), A distinção: crítica social do julgamento. São Paulo: Edusp/ /Porto Alegre-RS: Zouk.

Bourdieu, Pierre (2008), A economia das trocas linguísticas: o que falar quer dizer. São Paulo: Edusp [2. ${ }^{a}$ ed.]

Caldeira, Teresa Pires do Rio (2003), Cidade de muros: crime, segregação e cidadania em São Paulo. São Paulo: Ed. 34/Edusp [2. ${ }^{a}$ ed.].

Calvino, Ítalo (1998), As cidades invisiveis. São Paulo: Companhia das Letras.

Canclini, Nestor García (2008), Consumidores e cidadãos: conflitos multiculturais da globalização. Rio de Janeiro: Editora UFRJ [7. ${ }^{a}$ ed.].

Certeau, Michel de (2003), A invenção do cotidiano. Petrópolis-RJ: Vozes [9. ${ }^{a}$ ed.].

Davis, Make (2009), Cidade de quartzo: escavando o futuro em Los Angeles. São Paulo: Boitempo.

Depaule, Jean-Charles; Topalov, Christian (2001), "A cidade através de suas palavras", in Maria Stella Bresciani (org.), Palavras da cidade. Porto Alegre: Ed. Universidade/ UFRGS, 17-38.

Douglas, Mary; Isherwood, Baron (2009), O mundo dos bens: para uma antropologia do consumo. Rio de Janeiro: Editora UFRJ.

Featherstone, Mike (2007), Cultura de consumo e pós-modernismo. São Paulo: Studio Nobel. 
Fortuna, Carlos; Santos Silva, Augusto (2005), "A cidade do lado da cultura: espacialidades sociais e modalidades de intermediação cultural", in Boaventura de Sousa Santos (org.), A globalização e as ciências sociais. São Paulo: Cortez, 419-469 [3. ' ed.].

Foucault, Michel (2004), Vigiar e punir: nascimento da prisão. Petrópolis-RJ: Vozes.

Freire, Ricardo (2008), 100 praias que valem a viagem: uma seleção das praias mais gostosas do Brasil. São Paulo: Ed. Globo.

Giddens, Anthony (1991), As consequências da modernidade. São Paulo: Edusp.

Goldenberg, Miriam (2007), Nu E Vestido: Dez antropólogos revelam a cultura do corpo carioca. Rio de Janeiro: Record [2. ${ }^{\text {a }}$ ed.].

Gondim, Linda Maria de Pontes (2007), O Dragão do Mar e a Fortaleza pós-moderna: cultura, patrimônio e imagem da cidade. São Paulo: Annablume.

Harvey, David (2004), Condição pós-moderna: uma pesquisa sobre as origens da mudança cultural. São Paulo: Edições Loyola [13. ${ }^{\text {e ed.]. }}$

Leite, Rogério Proença de Sousa (2001), Espaço público e política dos lugares: usos do patrimônio cultural na reinvenção contemporânea do Recife Antigo. Campinas-SP: [s. n.].

Linhares, Paulo (2013), Cidade de água e sal: por uma antropologia do litoral sem cana e sem açúcar. Fortaleza: Armazém da Cultura.

Maciel, Wellington (2010), O aeroporto e a cidade: usos e significados do espaço urbano na Fortaleza turística. Fortaleza: EdUECE.

Maciel, Wellington (2011), Tempos e espaços da Praia do Futuro: usos e classificação de uma zona liminar. Tese de doutorado apresentada ao curso de Pós-Graduação em Sociologia da Universidade Federal do Ceará, Fortaleza, Brasil.

Maffesoli, Michel (2014), O tempo das tribos: o declínio do individualismo nas sociedades de massas. Rio de Janeiro: Forense [5. ${ }^{\text {e ed.]. }}$

MMA/ MPOG, Brasil - Ministério do Meio Ambiente/ Ministério do Planejamento, Orçamento e Gestão (2002), Projeto Orla: Fundamentos para gestão integrada. Brasília: MMA/SQA; Brasília: MP/SPU.

O’Donnell, Júlia (2013), A invenção de Copacabana: culturas urbanas e estilos de vida no Rio de Janeiro (1890-1940). Rio de Janeiro: Zahar.

Sassen, Saskia (1996), La ville globale: New York, Londres e Tokyo. Paris: Descartes $\&$ Cie.

Smith, Neil (2006), "A gentrification generalizada: de uma anomalia local à 'regeneração' urbana como estratégia urbana global”, in Catherine Bidou-Zachariasen (org.), De volta à cidade: dos processos de gentrificação às políticas de "revitalização" dos centros urbanos. São Paulo: Annablume, 59-87.

Urry, John (2001), O olhar do turista: lazer e viagens nas sociedades contemporâneas. São Paulo: Studio Nobel. 
Woodward, Kathryn (2007), “Identidade e diferença: uma introdução teórica e conceitual”, in Tomaz Tadeu da Silva (org.), Identidade e diferença: a perspectiva dos estudos culturais. Petrópolis-RJ: Vozes [7. ${ }^{\text {a ed.]. }}$

Zukin, Sharon (1991), Landscapes of Power: From Detroit to Disney World. California: University of California Press.

Zukin, Sharon (2000), "Paisagens urbanas pós-modernas: mapeando cultura e poder”, in Antonio A. Arantes (org.), O espaço da diferença. Campinas-SP: Papirus, 80-103.

Artigo recebido a 12.08.2016

Aprovado para publicação a 07.06.2017

\section{Wellington Maciel}

Programa de Pós-Graduação em Sociologia/ Grupo de Pesquisa Gestão Pública e Desenvolvimento Urbano da Universidade Estadual do Ceará

Avenida Dr. Silas Munguba, 1700, Campus do Itaperi, Fortaleza, Ceará, Cep: 60714903, Brasil

Contacto: wellington.maciel@uece.br

\section{Social and Symbolic Borders in the Liminal Public Space: A Case Study}

This article discusses the emergence of what might be called the liminal public space and the nature of the inequalities that are structured according to the topographic conditions that give it substance. I seek to point out the specificity of the markings and of the social and symbolic boundaries, taking the Praia do Futuro in Fortaleza (Ceará, Brazil), as a typical case. It is argued that the character of the urban space and the social practices that individualize it inside a city are factors that cannot be overlooked when analyzing the new forms of inequality in contemporary Brazil. The particularity of this work is to contribute to the debate on the relationship between the urban space

\section{Frontières sociales et symboliques dans l'espace public liminaire: une étude de cas}

Cet article se penche sur l'émergence de ce que l'on pourrait appeler un espace public liminaire et sur la nature des inégalités qui se structurent en fonction des contraintes topographiques que lui donnent substance. Nous cherchons à souligner la spécificité des démarcations et des frontières sociales et symboliques, en prenant pour cas typique celui de la Praia do Futuro, à Fortaleza (Ceará, Brésil). Nous soutenons que la caractéristique de l'espace urbain et les pratiques sociales qui l'individualisent au sein d'une ville sont des facteurs qui ne sauraient être ignorés au cours de l'analyse de nouvelles formes d'inégalités dans le Brésil contemporain. La singularité de ce 
and symbolic appropriations associated with seaside leisure.

Keywords: beaches; leisure; Praia do Futuro; right to public space; social and symbolic boundaries. travail réside dans le fait qu'il contribue au débat sur l'articulation entre l' espace urbain et les appropriations symboliques associées au loisir de plage.

Mots-clés: droit à l'espace public; frontières sociales et symboliques; loisir; plages; Praia do Futuro. 
